\title{
Manifestações bucais de pacientes soropositivos para HIV/AIDS
}

\author{
Oral manifestations in seropositive patients for HIV/AIDS \\ Manifestaciones bucales de los pacientes seropositivos para el VIH/SIDA \\ Natália Calegari PAULIQUE ${ }^{1}$ \\ Marlene Cabral Coimbra da CRUZ $^{2}$ \\ Luciana Estevam SIMONATO ${ }^{3}$ \\ Lucieni Cristina Trovati MORETI ${ }^{4}$ \\ Karina Gonzales Câmara FERNANDES ${ }^{4}$ \\ ${ }^{1}$ Graduanda do Curso de Odontologia da Universidade Brasil, 15600-000 Fernandópolis - SP, Brasil \\ ${ }^{2}$ Professora das Disciplinas de Saúde Coletiva e Imaginologia do Curso de Odontologia da Universidade Brasil, \\ 15600-000 Fernandópolis - SP, Brasil \\ ${ }^{3}$ Professora das Disciplinas de Estomatologia e Semiologia do Curso de Odontologia da Universidade Brasil, \\ 15600-000 Fernandópolis - SP, Brasil \\ ${ }^{4}$ Professora das Disciplinas de Endodontia e Clínicas Integradas do Curso de Odontologia da Universidade Brasil, \\ 15600-000 Fernandópolis - SP, Brasil
}

\begin{abstract}
Resumo
Introdução: As lesões bucais ocorrem com frequência em pacientes infectados pelo vírus HIV, podendo ser a representação dos primeiros sinais da doença, o que torna importante o diagnóstico inicial precoce pelos cirurgiões-dentistas. Objetivo: Apresentar uma síntese das informações mais relevantes sobre as principais manifestações bucais em pacientes soropositivos para HIV/AIDS. Material e Método: Foi realizada uma revisão da literatura em livros e bases de dados eletrônicos. Resultados: Os pacientes soropositivos podem desenvolver várias lesões bucais e peribucais, que não são únicas para portadores do HIV, mas ocorrem em maior frequência quando associadas a imunossupressão. As mais prevalentes são Infecções Fúngicas (Candidíase e Queilite Angular), Infecções Bacterianas (Doença Periodontal e Gengivite Úlcero-Necrosante), Infecções Virais (Herpes Simples e Leucoplasia Pilosa Oral) e Lesões Neoplásicas (Sarcoma de Kaposi). Conclusão: O número de pacientes HIV/AIDS é elevado, e mesmo com os tratamentos atuais, a suscetibilidade à lesões bucais ainda é alta, sendo a candidíase pseudomembranosa a infecção mais comum. $\mathrm{O}$ cirurgiãodentista é imprescindível no diagnóstico precoce destas lesões para contribuir para uma melhor qualidade de vida dos pacientes.
\end{abstract}

Descritores: Síndrome de Imunodeficiência Adquirida; Infecções por HIV; Manifestações Bucais.

\begin{abstract}
Introduction: Oral lesions frequently occur in patients infected with the HIV virus, and may represent the first signs of the disease, therefore, the dentist represents important part in the early diagnosis. Objective: To present a summary of the most relevant information about the main oral manifestations in HIV/AIDS patients. Material and Methods: A review on books and electronic data bases was held. Results: Seropositive patients may develop various oral and peribuccal lesions, which are not unique to HIV patients, but occur more frequently when associated with immunosuppression. The most prevalent are Mycoses (Candidiasis and Cheilitis), Bacterial Infections (Periodontal Diseases and Necrotizing Ulcerative Gingivitis), Virus Diseases (Herpes Simplex and Hairy Leukoplakia) and Neoplasms (Kaposi Sarcoma). Conclusion: The number of HIV/AIDS patients is high, and, although the current treatments, the susceptibility to oral lesions is still elevated, with pseudomembranous candidiasis being the most common infection. The dental surgeon is essential in the early diagnosis of these lesions to contribute to a better life quality of ailing patients.

Descriptors: Acquired Immunodeficiency Syndrome; HIV Infections; Oral Manifestations.
\end{abstract}

\section{Resumen}

Introducción: Las lesiones orales se producen con frecuencia en los pacientes infectados con el VIH, y puede ser la representación de los primeros signos de la enfermedad, tan sea importante el diagnóstico inicial por los dentistas. Objetivo: Presentar una visión general de la información más relevante sobre las principales manifestaciones orales en pacientes seropositivos para el VIH/SIDA. Métodos: Una revisión de la literatura en las bases de datos electrónicas y libros se llevó a cabo. Resultados: Los pacientes con VIH pueden desarrollar diversas lesiones bucales y peribucales, que no son exclusivos de los portadores del VIH, pero ocurren más a menudo cuando se asocia con la inmunosupresión. El más frecuente son las Infecciones por micosis (candidiasis y queilitis), Infecciones bacterianas (enfermedades periodontales y gingivitis ulcerosa necrotizante), Virosis (herpes simple y leucoplasia vellosa) y neoplasias (Sarcoma de Kaposi). Conclusión: El número de pacientes con VIH/SIDA es alto, y, a pesar de las terapias actuales, la susceptibilidad a las lesiones orales sigue siendo alta, con la candidiasis pseudomembranosa considerada la infección más común. El dentista es esencial en el diagnóstico precoz de estas lesiones para contribuir a una mejor calidad de vida de los pacientes. Descriptores: Síndrome de Inmunodeficiencia Adquirida; Infecciones por VIH; Manifestaciones Bucales.

\section{INTRODUÇÃO}

No cenário mundial foram verificadas mudanças nos As lesões bucais e peribucais são comuns nos pacientes infectados pelo vírus HIV e podem representar os primeiros sinais da doença, antes mesmo das manifestações sistêmicas, o que torna essencial aos cirurgiões-dentistas, o conhecimento sobre essas manifestações bucais ${ }^{1}$.

A Síndrome da Imunodeficiência Adquirida (AIDS/SIDA) é uma doença causada pelo Vírus da Imunodeficiência Humana (HIV), que é um retrovírus adquirido principalmente por via sexual (sexo desprotegido) e via sanguínea (objetos perfuro-cortantes contaminados). O vírus do HIV se reproduz no corpo humano nos linfócitos T CD4+ (que são os "maestros" do sistema autoimune), tornando o corpo vulnerável à infecção por doenças oportunistas $^{2}$.

Foi reconhecida oficialmente como doença em 1981, em função de uma explosão de casos inexplicados de Sarcoma de Kaposi e de pneumonia por Pneumocystis 
carinii em homossexuais masculinos ocorridos em diversas cidades dos Estados Unidos ${ }^{3}$. Mas somente em 1983 o HIV foi isolado e em 1984 relacionado como causa da AIDS ${ }^{4}$.

O HIV é um vírus que promove uma infecção crônica dos linfócitos T CD4+, resultando em imunossupressão do paciente, favorecendo infecções oportunistas, o que se reflete também na imunidade da mucosa bucal ${ }^{5}$.

A infecção pelo vírus da imunodeficiência humana (HIV) é considerada uma pandemia mundial, com casos notificados em quase todos os países ${ }^{6}$. De 1980 a junho de 2016, foram notificados no Brasil 842.710 casos de AIDS, sendo $548.850(65,1 \%)$ no sexo masculino e 293.685 $(34,9 \%)$ no feminino. A maior concentração dos casos de aids no Brasil está nos indivíduos com idade entre 25 e 39 anos para ambos os sexos; entre os homens, essa faixa etária corresponde a $53,0 \%$ e, entre as mulheres, a $49,4 \%$ do total de casos registrados de 1980 a junho de $2016^{7}$.

Em 2013 a taxa de incidência estava em 17,9 casos / 100 mil habitantes. Já a prevalência de infecção pelo HIV incluindo o estado assintomático é de $0,6 \%$ da população geral $^{4}$.

Com o advento das terapias antirretrovirais, houve uma diminuição na mortalidade e também nas doenças associadas ao HIV, aumentando assim a expectativa de vida destes pacientes, e consequentemente, o surgimento de doenças crônicas ${ }^{8}$.

Diversos trabalhos sobre as manifestações bucais de pacientes HIV/AIDS, mostraram a predominância de alguns tipos de lesões como a candidíase nas suas diversas formas clínicas, as doenças gengivais e periodontais, a leucoplasia pilosa, o sarcoma de Kaposi e o herpes simples ${ }^{3}$.

O objetivo deste estudo é buscar na literatura as principais doenças bucais que predominam em pacientes com HIV/AIDS

\section{MATERIAL E MÉTODO}

Trata-se de uma revisão bibliográfica de 38 documentos, dentre eles artigos científicos, periódicos, livros e informações do Ministério da Saúde relacionados ao tema. As buscas foram realizadas bases de dados eletrônicos como: Biblioteca Virtual em Saúde, Lilacs e SciELO.

\section{RESULTADOS E DISCUSSÃO}

Os pacientes HIV positivos podem desenvolver lesões bucais como: Candidíase, Doença Periodontal, Gengivite Ulcerativa Necrosante, Sarcoma de Kaposi, Leocoplasia Pilosa e Herpes Simples. Apresentam maior risco pacientes com menor escolaridade, menor renda, maior consumo de cigarros, dependência ao álcool, maior tempo de infecção pelo HIV e carga viral mais elevada no momento do exame?

Alguns pesquisadores dividiram as manifestações associadas à infecção pelo HIV em três grupos, segundo o qual os grupos I e II representam as lesões de ocorrência na região de cabeça e pescoço, mais e menos frequentes respectivamente, já o grupo III abrange lesões possivelmente associadas com infecção pelo $\mathrm{HIV}^{10}$. No grupo I estão as lesões orais mais comumente associadas com infecção pelo HIV, como a candidíase, leucoplasia pilosa, Gengivite Úlcero Necrosante (GUN) e sarcoma de Kaposi. No grupo II estão as infecções virais por citomegalovírus (CMV) e vírus herpes, papiloma vírus e varicela-zoster, e são menos comuns de ocorrerem. O grupo III abrange lesões como por exemplo a osteomielite ${ }^{11}$.

Estas lesões não são únicas para portadores do HIV, mas o aparecimento de algumas lesões bucais são fortemente sugestivas de comprometimento da resposta imune, por isso $\mathrm{o}$ aparecimento nesses pacientes ${ }^{12}$. Estas podem ser fúngicas, bacterianas e virais, além de processos neoplásicos e lesões de natureza desconhecida ${ }^{9}$.

Em estudo realizado por Souza $^{3}$ (2000), foram examinados 100 pacientes com AIDS internados no setor de AIDS em Hospital em Natal/RN/Brasil, e foi verificada presença de manifestações orais em que a manifestação mais frequente foi a Candidíase, seguida da gengivite e periodontite, leucoplasia pilosa e sarcoma de Kaposi. Dentre as lesões de candidíase, as mais presentes foram a pseudomembranosa seguida da queilite angular.

Em pesquisa realizada por Flores et al. ${ }^{13}$ (2006), em 130 prontuários avaliados de pacientes em Santa Maria/RS/Brasil, as manifestações bucais mais comuns foram a candidíase oral, herpes zoster, herpes simples, leucoplasia pilosa, sarcoma de Kaposi e GUN.

Em outro estudo com também 100 pacientes HIV/AIDS em Amazonas/Brasil, as manifestações bucais mais frequentes foram a candidíase (54\%), nas formas pseudomembranosa, eritematosa e queilite angular, a gengivite $(25 \%)$, a periodontite $(18 \%)$, a estomatite aftosa recorrente $(7 \%)$, a leucoplasia pilosa $(5 \%)$, o sarcoma de Kaposi (5\%), a infecção pelo citomegalovírus (3\%), o herpes simples (2\%) e o herpes zoster (2\%). Apenas $13 \%$ dos pacientes não apresentaram qualquer manifestação bucal ${ }^{10}$.

Já Gasparin et al. ${ }^{9}$ (2009), verificou a prevalência de $39 \%$ de lesões bucais nos 300 pacientes estudados em Rio Grande/RS/Brasil, e a manifestação estomatológica mais prevalente foi a candidíase, com $59,1 \%$, sendo $10,7 \%$ na forma de queilite angular; a leucoplasia pilosa com $25,2 \%$; herpes com 5,7\% e nenhuma lesão de sarcoma de Kaposi.

Motta et al. ${ }^{1}$ (2014) verificou que as alterações intrabucais mais prevalentes em 40 pacinetes estudados foram: a candidose pseudomembranosa $(19,23 \%)$, seguida da periodontite úlcero necrosante $(15,38 \%)$, da leucoplasia pilosa $(11,54 \%)$ e da queilite angular $(11,54 \%)$.

Em pacientes HIV positivos, alguns fatores podem contribuir para o desenvolvimento precoce dessas lesões: contagem de linfócitos TCD4+ abaixo de 200 células/mm3, carga viral elevada, xerostomia, higiene bucal precária e uso de tabaco $^{14}$.

Com o uso da terapia antirretroviral (TARV) aconteceram mudanças na frequência e nas características das complicações bucais associadas à infecção pelo HIV, pois esta reduz a carga viral e, como consequência, reduz a prevalência e a severidade de doenças oportunistas associadas ao $\mathrm{HIV}^{1}$.

Descreveremos a seguir as lesões mais prevalentes em Infecções Fúngicas (Candidíase e Queilite Angular), Infecções Bacterianas (Doença Periodontal e Gengivite Úlcero-Necrosante), Infecções Virais (Herpes Simples e Leucoplasia Pilosa Oral) e Lesões Neoplásicas (Sarcoma de Kaposi), segundo diversos estudos já realizados.

\section{Infecções Fúngicas}

\subsection{Candidíase}

Candidíase ou Candidose é um infecção fúngica oportunista causada pela Candida albicans. Existem 4 tipos de infecção por cândida: a pseudomembranosa, a eritematosa, a hiperplásica e a queilite angular ${ }^{15}$. É a lesão bucal mais comum nos pacientes com HIV/AIDS, estando relacionada a baixa imunidade do paciente ${ }^{16}$

A Candidíase Pseudomembranosa, forma mais comum nestes pacientes, caracteriza-se pela presença de pseudomembranas esbranquiçadas ou amareladas, 
facilmente removíveis por raspagem ${ }^{17}$.

Em indivíduos infectados pelo HIV assintomáticos é um sinal de descompensação imunológica e com frequência anuncia a transição para AIDS $^{18}$. Dependendo das condições imunológicas do paciente, a candidíase pode afetar outras áreas do corpo como a faringe, traqueia e o esôfago ${ }^{19}$.

O diagnóstico é feito clinicamente pelos sinais clínicos e exame de citologia esfoliativa, com identificação definitiva por meio de cultura ${ }^{20}$.

A primeira escolha de tratamento é a Nistatina 200.000 UI, suspensão oral ou pastilha diariamente 4-5 vezes por 10-14 dias. Também pode ser indicado, o Cetoconazol, o Fluconazol ou o Itraconazol (uso sistêmico) também são bem indicados nesses casos ${ }^{20}$.

Nestes pacientes, as lesões por Candida apresentam uma maior gravidade e resistência ao tratamento convencional $^{21}$.

\subsection{Queilite Angular}

É muito comum a presença de queilite angular em pacientes debilitados (devido à carência de vitaminas) e naqueles que já perderam molares (pela perda da dimensão vertical de oclusão). Como consequência, acontece a formação de uma dobra na comissura labial, deixando-a constantemente úmida e tornando o local propício para o desenvolvimento da candidíase ${ }^{20}$.

Ela apresenta-se como fissuras partindo da comissura labial, com presença de eritema e por vezes, placas esbranquiçadas. São frequentemente acompanhadas por candidíase intra-oral ${ }^{17}$.

\section{Infecções Bacterianas}

\subsection{Doença Periodontal}

Em relação as lesões de origem bacterianas associadas às infecções pelo HIV, estão a gengivite $\mathrm{e}$ periodontite de evolução rápida. Devido à imunossupressão decorrente da contaminação com o vírus da AIDS, ocorre alterações na microbiota oral, propiciando o desenvolvimento de lesões gengivais e periodontais ${ }^{9}$.

Entre os fatores de risco associados à doença periodontal, podem-se caracterizar os fatores sociais e comportamentais (fumo, álcool, drogas), além dos fatores sistêmicos, como infecção pelo $\mathrm{HIV}^{22}$. Observa-se que a saúde periodontal depende da interação dos fatores de risco com os mecanismos imunológicos ${ }^{23}$.

Segundo Glick e Holmstrup ${ }^{24}$ (2002), a imunodeficiência causada pelo HIV pode ter uma influência direta sobre a patogênese da doença periodontal. Assim, indivíduos infectados pelo HIV exibem lesões bucais frequentemente associadas à imunossupressão, as quais são causadas por patógenos oportunistas.

Com o início da Terapia Anti-Retroviral (TARV) combinada, alguns pesquisadores verificaram a redução acentuada na ocorrência de infecções oportunistas e na prevalência das manifestações bucais. Isso ocorre devido à recuperação parcial da função imunológica após supressão da viremia e redução da destruição celular causada pelo HIV $^{9}$

\subsection{Gengivite Ulcerativa Necrosante (GUN)}

Segundo Neville et al. ${ }^{20}$ (2008) a GUN é uma inflamação da gengiva caracterizada por lesões necróticas na margem papilar, epitélio necrosante pseudomembranoso, gosto metálico, odor fétido, sangramento espontâneo e extrema sensibilidade dolorosa. A infecção ocorre na presença de estresse psicológico e estados de imunossupressão, principalmente associados com a AIDS. Sua prevalência na população normal é menor que $0,1 \%$. Os agentes etiológicos da GUN são bactérias anaeróbias como a Prevotella intermedia, as fusobactérias e as espiroquetas.

Com a imunossupressão ocorrem alterações na microbiota normal da boca, com aumento das bactérias anaeróbias gram-negativas subgengivais propiciando lesões gengivais e periodontais ${ }^{3}$.

O tratamento da GUN consiste inicialmente de uma irrigação da área com água oxigenada, visto que os principais microrganismos causadores são anaeróbicos e localizam-se próximos à superfície externa da gengiva e remoção das membranas necróticas com gaze estéril embebida em clorexidina a $0,12 \%$. Devem ser prescritos bochechos com clorexidina ou água oxigenada diluída, antibióticos (ex.: metronidazol, penicilina, eritromicina, tetraciclina), além de instruções de higiene oral, repouso e dieta nutritiva de consistência branda. Após a terapia inicial, é feito o tratamento periodontal básico ${ }^{20}$.

A PUN, diferencia-se da GUN pela perda óssea alveolar e de inserção clínica, apresentando ulceração local e necrose do tecido gengival, expondo o osso subjacente e destruindo-o rapidamente, ocorrendo também sangramento espontâneo e dor grave. O tratamento é o mesmo da GUN, porém o prognóstico é muito desfavorável ${ }^{15}$.

\section{Infecções Virais}

\subsection{Herpes Simples}

O herpes simples representa a doença viral mais comum no homem moderno. Em pacientes imunocomprometidos, as infecções herpéticas podem provocar severas complicações ${ }^{25}$.

As infecções pelos vírus herpes simples (HSV-1 e HSV-2) representam, entre as doenças sexualmente transmissíveis, as mais comuns a nível global, alcançando uma soro prevalência de $80 \%$ em adultos ${ }^{26}$.

Nos pacientes portadores de HIV ou de qualquer outra doença autoimune, a infecção pelo HSV-1 manifesta-se com maior frequência, quando comparada aos pacientes imunocompetentes, devido à debilidade do sistema imunológico $^{27}$.

As lesões geralmente são vesiculares, que coalescem e ulceram sobre uma base eritematosa formando uma crosta serosa e cicatrizam nas semanas seguintes ${ }^{28}$. Na mucosa bucal de pacientes imunocompetentes, ocorre, principalmente no palato duro, gengiva, dorso lingual e vermelhão do lábio ${ }^{29}$.

As lesões recorrentes do herpes simples são altamente contagiosas para os pacientes, suas famílias, profissionais da saúde e auxiliares ${ }^{30}$. O herpes pode ser uma fonte de dores, desconforto e de ansiedade e um tratamento adequado faz-se necessário $^{31}$

A natureza viral do herpes simples recorrente peribucal e intrabucal requer uma terapêutica antiviral eficiente, que promova a chegada do medicamento até o interior das lesões. Essa necessidade implica em uma terapêutica antiviral por via oral, com absorção intestinal e cujas moléculas viabilizem sua chegada nas lesões através da corrente sanguínea ${ }^{29}$.

Entre as principais drogas antivirais disponíveis para administração sistêmica estão os seguintes produtos: aciclovir, valaciclovir, penciclovir e famciclovir. Em pacientes imunocompetentes portadores de herpes simples recorrente peribucal e intrabucal, Consolaro e Consolaro ${ }^{29}$ (2009) prescreveram durante 12 anos de trabalho observado, o valaciclovir: um comprimido de $500 \mathrm{mg}$ a cada 12 horas durante 5 dias, a cada surto, o que 
reduziu o desconforto e o tempo de duração das lesões em até dois dias.

A aplicação clínica da radiação do laser de baixa potência para o tratamento de dor aguda e crônica é hoje uma procedimento bem estabelecido, e sua aplicação nos casos de herpes simples mostra grande alívio ao paciente acometido, favorecendo a interrupção e reparação rápida do quadro 31

\subsection{Leucoplasia Pilosa Oral}

A leucoplasia pilosa oral (LPO) é uma infecção oportunista associada à presença do vírus Epstein-Barr (EBV) e se apresenta de modo especial nos pacientes infectados pelo HIV $^{13}$.

A leucoplasia pilosa foi descrita pela primeira vez por sua ocorrência em homossexuais masculinos, soropositivos para o HIV. A LPO manifesta-se clinicamente como uma placa branca, não removível à raspagem, localizada principalmente nas bordas laterais da língua, uni ou bilateralmente $^{17}$. A superfície pode apresentar-se plana, corrugada ou pilosa, sendo seus aspectos clínicos característicos, porém não patognomônicos ${ }^{32}$.

Na maioria dos casos, a LPO é assintomática ou não apresenta sintomatologia relevante. De acordo com Greenspan et al. ${ }^{33}$ (1984), em alguns casos, pode haver dor e ardência e, até mesmo de comprometimento estético para o paciente, em que o tratamento se faz necessário.

A importância da LPO no diagnóstico e prognóstico da AIDS justifica a necessidade da precocidade e precisão diagnóstica, sendo que alguns estudos já apontam a citopatologia como método diagnóstico de escolha ${ }^{11}$.

$\mathrm{Na}$ infecção pelo HIV, a LPO acomete preferencialmente pacientes adultos, com uma prevalência de $28 \%$ dos homens homossexuais no início da epidemia em 1984, sendo que essa mesma prevalência foi encontrada em outro estudo realizado em uma população brasileira ${ }^{33}$. Porém, com a implantação das novas terapias antirretrovirais, os casos de LPO, assim como outras manifestações bucais, estão ocorrendo com menor frequência ${ }^{34}$.

$\mathrm{O}$ tratamento pode ser desnecessário. $\mathrm{O}$ aciclovir ou o desiclovir produzem uma rápida resolução, mas a recorrência é esperada com a descontinuidade do tratamento ${ }^{20}$

\section{Lesões Neoplásicas}

\subsection{Sarcoma de Kaposi}

Morris Kaposi, em 1872, descreveu uma nova patologia que acometia, predominantemente, idosos do sexo masculino, com lesões múltiplas, hiperpigmentadas, nodulares e de ocorrência mais frequente nas extremidades dos membros inferiores, que mais tarde, passaria a ser conhecida como Sarcoma de Kaposi (SK) ${ }^{35}$.

É um tumor vascular, sendo mais comum em pacientes com aids, e predominantemente em homens. Existem evidências de que o herpes vírus humano tipo 8 seja o principal co-fator na manifestação dessa neoplasia ${ }^{36}$.

A infecção pelo HIV não é um pré-requisito para o desenvolvimento do SK já que estudos moleculares não conseguiram detectar esse vírus no tecido neoplásico, o que torna improvável que o HIV desempenhe um papel oncogênico direto na etiologia do $\mathrm{SK}^{37}$.

As lesões da cavidade oral ocorrem em aproximadamente um terço dos pacientes com KS associado à Aids, sendo que as lesões duras do palato são as mais comuns. Estas lesões, placas vermelhas ou roxas, focais ou difusas, podem ser completamente assintomáticas e facilmente negligenciáveis. Estas lesões podem interferir com comer e falar, causar perdas dentais, ou comprometer as vias aéreas ${ }^{38}$.

$\mathrm{O}$ diagnóstico definitivo requer a biópsia. O tratamento para SK inclui radiação, excisão cirúrgica e injeções intra-lesionais com quimioterápico. A maior parte desses tratamentos não cura, mas reduz o tamanho e o número. Estudos recentes mostram alguma eficácia com agentes anti-angiogenesis, tais como talidomida e ácido retinóico $^{12}$

\section{CONCLUSÃO}

Mesmo com os tratamentos atuais, que elevam a expectativa de vida dos pacientes soropositivos, a suscetibilidade à lesões bucais ainda é alta, sendo a candidíase pseudomembranosa a infecção mais comum, seguida da queilite angular e doenças periodontais.

O número de pacientes soropositivos aumenta a cada dia, e o cirurgião-dentista se torna imprescindível no reconhecimento precoce destas manifestações bucais associadas ao HIV, para que possa contribuir para uma melhor qualidade de vida dos pacientes.

\section{REFERÊNCIAS}

1. Motta WKS, Nóbrega DRM, Santos MGC, Gomes DQC, Godoy GP, Pereira JV. Aspectos demográficos e manifestações clínicas bucais de pacientes soropositivos para o HIV/Aids. Rev Odontol UNESP. 2014; 43(1):61-7.

2. BRASIL. Ministério da Saúde. Secretaria de Atenção à Saúde. Departamento de Atenção Básica. HIV/Aids, hepatites e outras DST / Ministério da Saúde, Secretaria de Atenção à Saúde, Departamento de Atenção Básica. Brasília: Ministério da Saúde, 2006. 197 p. il. (Cadernos de Atenção Básica, n. 18) (Série A. Normas e Manuais Técnicos).

3. Souza LB, Pinto LP, Medeiros AMC, Araújo Jr RF, Mesquita OJX. Manifestações orais em pacientes com AIDS em uma população brasileira. Pesq Odont Bras. 2000;14(1):79-85.

4. Engel C. MEDGRUPO. Infectologia: Síndrome da Imunodeficiência Adquirida/AIDS. Ciclo 1: Medcurso. 2v. São Paulo: MedyKlin; 2013.

5. Mattos SL, Santos VR, Ferreira EF. Prevalência de lesões de mucosa bucal em pacientes HIV positivos de Unidade de Referencia Especializada em Doenças Infecciosas e Parasitarias Especiais -URE- DIPE (Belém-Pará). Rev bras patol oral. 2004; 3(1):7-16.

6. Sanjar FA, Queiroz BEUP, Miziara ID. Otolaryngologic manifestations in HIV disease-clinical aspects and treatment. Braz J Otorhinolaryngol. 2011;77(3):391-400.

7. BRASIL. Ministério da Saúde. Secretaria de Vigilância em Saúde. Boletim Epidemiológico - Aids e DST, 2016. Ano $\mathrm{V}, \mathrm{n}^{\circ} 1$.

8. Yin MT, Dobkin JF, Grbic JT. Epidemiology, pathogenesis, and management of human immunodeficiency virus infection in patients with periodontal disease. Periodontol 2000. 2007; 44(1):55-81.

9. Gasparin AB, Ferreira FV, Danesi CC, Sassi RA, Silveira J, Martinez AMB, et al. Fatores e prevalências associados às manifestações bucais em pacientes HIV positivos atendidos em cidades sul-brasileiras. $\mathrm{Cad}$ Saúde Pública. 2009; 25(6):1307-15.

10. Chagas MV, Santos LO, Ono, LM. Manifestações bucais de Pacientes HIV Atendidos na Fundação de 
Medicina Tropical do Amazonas (FMT-AM). Rev Fac Odontol Porto Alegre. 2009; 50(3):10-3.

11. Axell T, Baert S, Brocheriou C, Challa Combe S, Greenspan D, Kate RW, et al. Revised classification of HIV - associated oral lesions. Brit den J. 1991; 170(8):305-6.

12. Hirata $\mathrm{CH}$. Oral manifestations in AIDS. Braz $\mathrm{j}$ otorhinolaryngol. 2015; 81:120-3.

13. Flores JA, Ferreira FV, Gasparin AB, Kaiser MR, Oliveira MO. Manifestações bucais e infecções oportunistas em pacientes HIV positivos no Hospital Universitário de Santa Maria (HUSM) - RS. Saúde, Santa Maria. 2006; 32(1):45-52.

14. Aguirre-Urízar JM, Echebarría-Goicouría MA, EguíaDel Valle A. Síndrome de inmunodeficiencia adquirida: manifestaciones en la cavidad bucal. Med Oral Patol Oral Cir Bucal. 2004; 9(Suppl):148-57.

15. Ribeiro MP, Dal Castel MMB, Costa TOC, Chevalier ALN, Montenegro FLB, Miranda AF. Odontogeriatria: AIDS na população idosa do Brasil e a falta de programas de prevenção. Rev Portal Divulg. 2015; 5(44):25-32.

16. Lemos AD. AIDS na terceira idade. Campina Grande. Monografia [Graduação] - Universidade Estadual da Paraíba; 2012.

17. BRASIL. Ministério da Saúde. Secretaria de Políticas de Saúde. Coordenação Nacional de DST e AIDS. Controle de infecções e a prática Odontológica em tempos de AIDS: manual de condutas. Brasília: Ministério da Saúde; 2000. 118p.

18. Cotran RS, Kumar V, Collins T. Doenças da imunidade. In: Robbins SL. Patologia estrutural e funcional. 6. ed. Rio de Janeiro: Guanabara Koogan; 2000. Cap. 7, p.168232.

19. Patton LL. HIV Disease. Dent Clin North Am. 2003; 47(3):467-92.

20. Neville BW, Damm DD, Allen CM, Bouquot JE. Patologia Oral \& Maxilofacial. 2. Ed. Rio de Janeiro: Guanabara Koogan; 2008.

21. Quart AM Espinel-Ingroff A, Moore LS, Reich D. Evaluation of fluconazole in the treatment of oropheryngeal candidiasis in patients with AIDS. Infect Med. 1996; 13(8):708-13.

22. Graham H. Behaving well: women's health behavior in context. In: Roberts H, editor. Women's Health Counts London: Routledge; 1990.

23. Grossi SG, Zambon JJ, Ho AW, Koch G, Dunford RG, Matchei EE et al. Assessment of risk for periodontal disease. I. Risk indicators for attachment loss. J Periodontol. 1994; 65(3):260-7.

24. Glick M, Holmstrup P. HIV infection and periodontal disease. In: Rose LF, Genco RJ, Cohen DW, Mealey BL, edictors. Periodontal Medice. London: BC Decker Inc; 2000. p.183-93.

25. Fatahzadeh M, Schwartz RA. Human herpes simplex infections: epidemiology, pathogenesis, symptomatology, diagnosis and management. Clin Exp Dermatol. 2007; 32(5):625-30.

26. Engelberg R, Carrell D, Krantz E, Corey L. Wald A. Natural history of genital herpes simplex virus type 1 infection. Sex Transm Dis. 2003; 30(2):174-7.

27. Tagliari NAB, Kelmann RG, Diefenthaler H. Aspectos terapêuticos das infecções causadas pelo vírus herpes simples tipo 1. Perspectiva. 2012; 36(133):191-201.
28. Trindade AKF, Queiroga ASD, Campos S, Lucena L, Sousa E. Herpes simples labial - um desafio terapêutico. Comun Ciênc Saúde. 2007; 18(4):307-14.

29. Consolaro A, Consolaro MF. Diagnóstico e tratamento do herpes simples recorrente peribucal e intrabucal na prática ortodôntica. R Dent Press Ortodon Ortop Facial. 2009; 14(3):16-24.

30. Siegel MA. Diagnosis and management of recurrent herpes simplex infections. J Am Dent Assoc. 2002; 133(9): 1245-9.

31. Reggiori MG, Allegretti CE, Scabar LF, Armonia PL, Giovani EM. Terapia a laser no tratamento de herpes simples em pacientes HIV: relato de caso. Rev Inst Ciênc Saúde. 2008;26(3):357-61.

32. Eversole LR, Jacobsen P, Stone CE, Freckleton V. Oral condyloma planus (hairy leukoplakia) among homosexual men: a clinicopathologic study of thirty-six cases. Oral Surg. 1986; 61(3):249-55.

33. Greenspan D, Greenspan JS, Conant M, Petersen V, Silverman JRS, Souza Y. Oral hairy leukoplakia in male homosexuals: evidence of associati on with both papilloma virus and a herpesgroup virus. Lancet. 1984; 2(8407):831-4.

34. Tappuni AR, Fleming GJ. The effect of antiretroviral therapy on the prevalence of oral manifestations in HIVinfected patients: a UK study. Oral Surg Oral Med Oral Pathol Oral Radiol Endod. 2001; 92(6):623-8.

35. Zurrida $\mathrm{S}$ et al. Classic Kaposi's sarcoma: a review of 90 cases. J Dermatol. 1992. 19(9):548-52.

36. Corrêa, Elisabete Míriam de Carvalho; Andrade, Eduardo Dias. Tratamento odontológico em pacientes hiv/aids. Rev odonto ciênc. 2005; 20(49):281-9.

37. Biggar RJ. Cancer in acquired immunodeficiency syndrome: An epidemiological assessment. Semin Oncol. 1990. 17(3):251-60.

38. Costa EL, Venâncio MA, Gamona A. Sarcoma de Kaposi. HU rev, Juiz de Fora. 2006; 32(3):77-84.

\section{CONFLITO DE INTERESSES}

Os autores declaram não haver conflitos de interesse.

\section{AUTOR PARA CORRESPONDÊNCIA}

Marlene Cabral Coimbra da Cruz

mcoimbracruz@gmail.com

Submetido em 11/03/2017 Aceito em 02/05/2017 